\title{
Morphofunctional Relationship of Gallbladder Pathology with Stomach Pathology in the Conditions of Kara-Suu General Practice Centers. Influence of the Trophological Status to Stone Formation
}

\section{Turusbekova AK, Kalmatov RK, Moldoev M*, Zhanadilova GZH and Kalysbek KS}

Department of Public Health, Osh State University, Kyrgyzstan

*Corresponding Author: Moldoev M, Department of Public Health, Osh State University, Kyrgyzstan.
Received: November 22, 2021

Published: December 29, 2021

(C) All rights are reserved by Moldoev M., et al.

\begin{abstract}
The study of the influence of the trophological status of patients on the course of pathologies of the gallbladder and stomach, physicochemical changes in bile and the state of the gastric mucosa can improve the results of treatment of combined pathologies of the hepatobiliary zone. The introduction into practice of gastroscopic studies of patients with cholelithiasis can substantiate the pathogenicity of the treatment of pathologies of neighboring organs.
\end{abstract}

Keywords: Organs; Gallbladder; Stomach

\section{Introduction}

Features of calculous cholecystitis in differential body mass indexes (BMI).

In this study learned dynamic changes in the gastric mucosa and secretion of bile from the duodenal nipple in patients with gallstone disease with dyspepsia and pain syndrome in the epigastric and right hypochondriac region.

In this study, 71patients got treatment, who were divided into two groups: 43 patients, who didn't get gastroscopy examination (group number 2), were analyzed and contrasted with 28 patients who took gastroscopy examination (control group).

All patients underwent laparoscopic cholecystectomy. In the postoperative period, antibiotic therapy was performed.
Gallbladder disease - multifactorial and multistage disease, characterized with cholesterol and bilirubin metabolism disorders with the formation of stones in the gallbladder and/or bile ducts.

The incidence of gallstone disease among residents in the $3^{\text {rd }}$ place in industrially developed countries, it is prevalent after cardiovascular diseases and diabetes mellitus. The diagnosis and treatment of cholelithiasis and its complications to this day remains one of the main and most studied areas of clinical medicine and abdominal surgery [41,42]. Gallstone disease is a significant economic burden for health care in many countries of the world $[29,43]$. Cholecystectomy (CE), especially laparoscopic CE (LCE), is the most frequent surgical intervention, that even pushed appendectomy to the second position $[28,30]$. At the same time, the effectiveness of treatment increased significantly [40], and mortality rate decreased [39]. Obesity has always been considered one of 
the main risk factors for the development of cholelithiasis [37,38]. However, in recent years, gallstones have become ubiquitous in persons with normal and low body weight [1]. The reasons for this phenomenon are not clear and require clarification, especially since young people have become susceptible to gallstone disease, including not only women, but also men [2]. In the available local and foreign literature, no works were found highlighting the features of the course of combinations of pathology of the gallbladder and stomach in patients with different body weights. The need to further improve the results of diagnosis and treatment due to the high likelihood of developing a variety of complications is not only a medical, but also a social problem $[6,9,35]$. Currently, there is growing interest in the study of the role of changes in the physicochemical properties of bile and gastric juice, factors of trophological status in the blood (leptin, insulin), pro-inflammatory cytokines, etc. in patients with different trophological status. The study of this issue is of practical importance, since the need to address these issues can serve as the basis for solving the economic burden on the state, reducing the days of inabiliity to work of patients of working age, shortening time of patients in hospitals. A clear dependence of the functional state of the gallbladder on the amount of adipose tissue has been established - the likelihood of hypokinesia increases with an increase in the specific gravity of adipose tissue. Among patients aged 25-45 years, cholelithiasis occurs in every fifth [1], which undoubtedly affects the socio-economic state of the country [3]. For practical healthcare, it is important to introduce accurate, timely methods of diagnosis and treatment of the disease in order to identify concomitant pathologies and reduce the number of complications, incl. operational benefits, which will reduce the socio-economic burden [4].

In Kara-Suu territorial hospital, the number of operated patients with calculous cholecystitis in 9 months of 2021 is 71, of which 28 patients underwent gastroscopy. A wide range of diagnostic and therapeutic methods has led to a revision of the strategy and tactics for cholelithiasis. Naturally, it became necessary to optimize the choice of diagnostic tests and treatment methods individually for each patient.

Cholecystectomy does not eliminate the complex pathophysiological foundations formed during gallstone formation of the digestive processes, which are subsequently realized in violation of the deposition, absorption and digestion of food. The main link in the dysfunction of the gastroduodenal zone is generally recognized as a deficiency of gastric and pancreatic enzymes.

In most cases, chronic cholecystitis is combined with stomach pathology. Inflammation of the stomach in gallstones is practically not paid attention, as evidenced by the lack of publications on this issue.

The aim of our study is to study the physicochemical changes in bile, gastric juice and gastric mucosa, the influence of trophological status factors on the course of calculous cholecystitis and gastric pathology, the main patterns of occurrence and the influence of trophological status on the development of this pathology.

\section{Research Data and Methods}

The results of the study are directly related to practical medicine and make it possible to expand the understanding of surgeons, therapists, gastroenterologists, endoscopists and doctors of other specialties on methods of diagnosis, prevention, treatment of calculous cholecystitis with gastric pathology in patients with different body weights, as well as postoperative rehabilitation depending on body weight. Determination of the level of the hormones leptin, insulin in the blood helps to predict the severity of the postoperative period in patients with calculous cholecystitis with stomach pathology and to adjust the therapy immediately after the operation.

71 patients with calculous cholecystitis were operated on the basis of Kara-Suu General practice centers. Patients are divided into 2 groups: patients who underwent gastroscopy; patients who refused gastroscopy and patients who did not require gastroscopy.

The patients included in this study, underwent general health assessment, laboratory diagnosis, diagnostic imaging techniques, functional and anthropometric measurements.

Patients of the first group were examined using a video gastroscope OLYMPUS CV-140 and the following changes were revealed: 8 patients had multiple erosive-hemorrhagic changes in the gastric mucosa, hypersalivation. In 2 patients, the mucous membrane of the duodenum is edematous with multiple small erosions, bile in the lumen of dark brown color, sticking of bile, large duodenal nipple edematous with the pancreatobiliary zone disease, in 3 patients in the lumen of the duodenum, bile is light yellow in color, the mucosa with foci of hyperemia due to chronic pancreatitis 
caused by chronic cholecystitis, peristalsis is preserved, folds are normal, large duodenal nipple is normal, in 4 patients catarrhal inflammation of the mucous membrane of the lower third part of the stomach, edema of the mucous membrane with symptoms of small erosions due to acute pancreatitis caused by acute cholecystitis, hyperemia and pyloric edema, in 11 patients increased size of the stomach, atonic, sluggish peristalsis, stretched folds, atrophic changes in the gastric mucosa. Chronic gastritis is also noted in the lower third part of the stomach, more in the antrum with superficial erosions.

\section{Research methodology and methods}

For work clinical and statistical research methods, laboratory and instrumental investigations were used. The object of the study is patients with uncomplicated and complicated calculous cholecystitis with different body weights. The subject of the research is the analysis of the factors of the relationship between the risk of calculous cholecystitis and gastric pathologies in individuals with different body weights.

The course of the postoperative period in patients with calculous cholecystitis depends on their body weight, the presence complications and accompanying pathologies. In contrast to patients with normal and low body weight, the postoperative period of patients with obesity aggravate non-alcoholic fatty liver disease, prolonged stone carriage and exacerbation of pancreatitis and gastric pathologies, in particular acute gastritis, erosive gastritis, and stress ulcers.

The medical histories of 71 patients with cholelithiasis were studied, who were operated in the Kara-Suu general practice centers in 2021for 10 months. All patients underwent laparoscopic surgery.

Almost all patients had complaints of pain in the epigastrium and right hypochondrium, nausea and vomiting, only 3 had complaints of pain in the right hypochondrium without vomiting. Patients were divided into groups according to gender, age, weight and height (shown below).

\section{Results and its Discussion}

The clinical manifestations of chronic cholecystitis are very diverse, although in $17.77 \%$ of cases the disease is asymptomatic. A number of authors believe that the disease does not have specific highly sensitive symptoms at all; as a rule, it is a manifestation of stomach pathology. Until now, the pathogenesis of gallstone disease has not been sufficiently studied [20,21]. Modern concepts of gallstone diseases allow us to consider it as a systemic disease, some of the factors underlying, in addition to infection, metabolic and hormonal disorders play an important role, and the main reason - lipid distress syndrome [23,27,32,45]. Gallstone diseases is associated with other metabolic disorders like obesity, diabetes mellitus, hypothyroidism, and there are no gender differences in this $[22,23,26,34,32,46]$. So far, however, predisposing factors for the formation of stones are: obesity, female, old or senile age, physical inactivity, overeating of fatty and high-calorie foods, numerous pregnancies and childbirth in history, iatrogenic factors [16,33,34]. If we take into account that cholesterolemia in women in average lower than in men, then the prevalence of cholesterol in women is not clear $[47,48]$. Bile lithogenicity is higher in women than in men. There is a lot of evidence of connection between obesity and gallstone disease: hypercholesterolemia of obese, high intra-abdominal pressure, especially in abdominal obesity, impeding bile secretion, non-alcoholic fatty liver disease (NAFLD) affects [17$19,31,36]$.

Dysplasia of connective tissue can contribute to the development of gallstones: changes in the shape of the gallbladder (bends, hook shape, etc.) hinder bile secretion. The gallbladder is under complex hormonal influences. Two main mechanisms of the participation of hormones in the development of cholelithiasis can be identified: 1) the role of hormones in the processes of fat metabolism is great, and therefore in the regulation of the synthesis and decay of lipids, contributing to lipid "distress syndrome"; 2) hormones are involved in the pathogenesis of functional disorders of the biliary tract $[5,44]$. Changes in cholesterol, lipid and mineral metabolism, as well as bile secretion processes can largely be associated with endocrine disorders, with abnormalities in the secretion of hormones [5]. Cholecystokinin is produced by 16 neuroendocrine cells of the stomach, duodenum, and jejunum. Previously, it was believed that cholecystokinin is the main factor that carries out bile secretion: it reduces the tone of the sphincter of Oddi and causes contraction of the muscles of the gallbladder; The gallbladder is emptied. Cholecystokinin inhibits gastric secretion and triggers the secretion of pancreatic juice. It turned out that the effect of cholecystokinin is not only this. Bile secretion is stimulated by gastrin, secretin, vasoactive intestinal peptide (VIP), pancreazimin, 
insulin; inhibition of bile secretion is carried out by somatostatin, pancreatic polypeptide, anticholecystokinin, VIP, neurotensin, enkephalins, angiotensin, thyroid hormones (T3, T4). Secretin is a peptide hormone produced by S-cells of the gastric mucosa, duodenum, cells of the proximal small intestine; in chemical structure and function, secretin resembles glucagon and also inhibits insulin secretion. These hormones "help" cholecystokinin in stimulating gallbladder contraction. VIP accelerates biliary excretion and in the other hand, inhibits the contraction of the gallbladder stimulated by cholecystokinin. Somatostatin inhibits the secretion of many neuropeptides of the gastrointestinal tract (gastrin, secretin, cholecystokinin, VIP, enteroglucagon, motilin), as well as somatotropin, thyrotropin, insulin. Cortisol also decreases gallbladder motility; thyroid-stimulating hormone, thyroid hormones and insulin affect the physicochemical properties of bile. Leptin regulates the expression of the gene responsible for the secretion of cholecystokinin. A negative correlation was established between the level of adiponectin and visfatin and the occurrence of cholelithiasis. It is clear that not all hormonal factors involved in the pathogenesis of gallstone disease are already known and studied, but deviation from the norm of secretion of at least one of the listed hormones disrupts the formation of bile, regulation of the function of the gastrointestinal tract and the gastrointestinal tract [5]. Hormonal disturbances lead to gallbladder dysfunction, bile stasis and gallstones.

When conducting ultrasound, it is possible to examine the adjacent organs and determine the connection between the wall of the gastrointestinal tract and the liver parenchyma [14]. The presence of inflammation of the gallbladder and gallbladder is confirmed by biochemical and bacteriological studies [15].

The diagram shows the distribution by sex difference, which corresponds to the global trend indicated in the literature. Out of 24 patients, there were 4 men and 20 women.

According to gender distribution: 19,7 percent are males and 80,3 percent are females.

According to the age of patients: up to 30 years-6, up to 40 years-11, up to 50 years-19, up to 60 years -17 , up to 70 years-15, 80 years -3 .

According to the weight of patients: up to $50 \mathrm{~kg}-1$, up to $60 \mathrm{~kg}-9$, up to $70 \mathrm{~kg}-13$, up to $80 \mathrm{~kg}-17$, up to $90 \mathrm{~kg}-19$, up to $100 \mathrm{~kg}-8$, over $100 \mathrm{~kg}-5$.

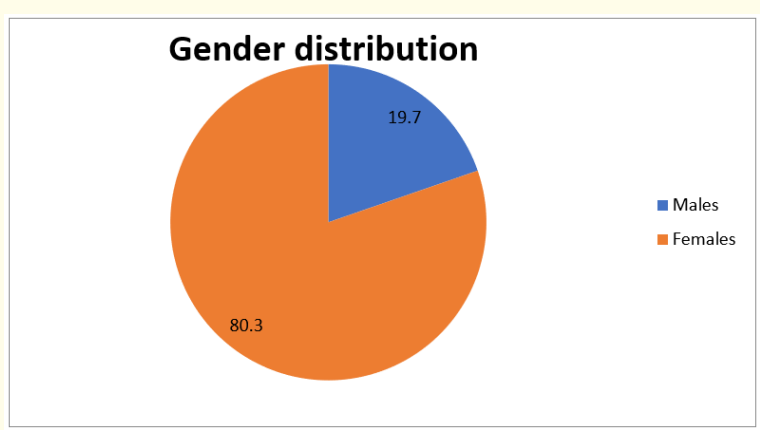

Chart 1: Gender distribution.

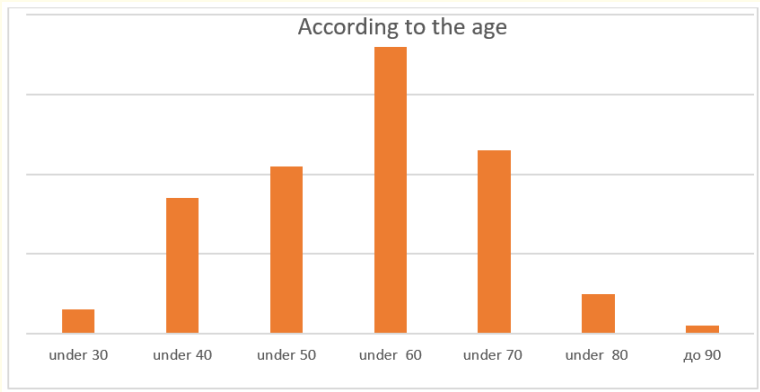

Chart 2: By age.

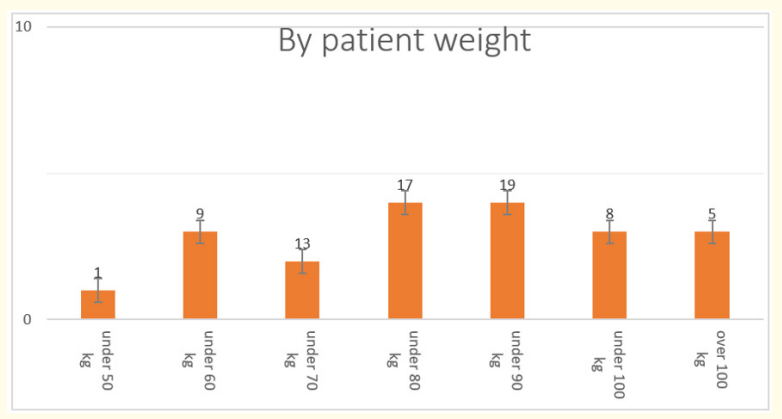

Chart 3: By patient weight.

\begin{tabular}{|c|c|c|}
\hline \multicolumn{3}{|c|}{ Distribution of patients by height } \\
\hline Under $\mathbf{1 6 0} \mathbf{~ c m}$ & Under $\mathbf{1 7 0} \mathbf{~ c m}$ & Under $\mathbf{1 8 0} \mathbf{~ c m}$ \\
\hline 15 & 23 & 7 \\
\hline
\end{tabular}

Table 1: According to the height of patients: up to $160 \mathrm{~cm}-15$; up to $170 \mathrm{~cm}-23$; up to $180-7$. 
To make the diagnosis, the following methods were used: clinical and anamnestic, laboratory, ultrasound, electrocardiography, patients over 60 years of age underwent an X-ray examination of the chest organs, for whom gastroscopy was performed for complaints of epigastric pain.

Out of 71 patients, only 7 gallbladder stones were detected for the first time, in 64 patients stone carriage lasted from 6 months to $5-7$ years.

The chronic form of cholecystitis can worsen at any time, it is impossible to predict it and it is often manifested by the clinic feature of acute gastritis. Patients with complaints of combined pain in the right hypochondrium and epigastric region with dyspeptic disorders account for almost $80 \%$ of the total number of patients.

According to ultrasound, all patients showed calculi in the gallbladder cavity, changes in the walls of the gallbladder in the form of thickening, in 4 cases of dissection of the gallbladder wall, deformation of the gallbladder, peripubular edema, etc., in 7 patients ultrasound data of a chronic process. Among the operated patients, hypotrophy in $4.2 \%$, normatrophy in $9.8 \%$, hypertrophy of varying degrees in $86 \%$ of patients, and this indicates the influence of trophological status on the development of the disease, which is also confirmed by the literary data, which are indicated in the data of S. N. Styazhkina, A.A. Valinurova, A.M. Shabardina, A.I. Ayupov [12].

\begin{tabular}{|c|c|c|c|c|c|c|c|}
\hline $\begin{array}{c}\text { Erosive } \\
\text { gastritis }\end{array}$ & $\begin{array}{c}\text { Chronic } \\
\text { pancreatitis }\end{array}$ & $\begin{array}{c}\text { Peptic ulcer and } \\
\text { duodenal ulcer }\end{array}$ & $\begin{array}{c}\text { Cardiovascula } \\
\text { rpathology }\end{array}$ & $\begin{array}{c}\text { Respiratory } \\
\text { system pathology }\end{array}$ & Diabetes & cirrhosis & $\begin{array}{c}\text { Pathology of the } \\
\text { genitourinary system }\end{array}$ \\
\hline 21 & 7 & 3 & 18 & 5 & 6 & 3 & 5 \\
\hline
\end{tabular}

Table 2: Comorbidities of the examined patients.

68 patients with concomitant diseases, Erosive gastritis - 21, Chronic pancreatitis - 7, Peptic ulcer and duodenal ulcer - 3, Cardiovascularpathology - 18, Respiratory system pathology - 5, Diabetes - 6, cirrhosis - 3, Pathology of the genitourinary system - 5 .

Blood test results: hemoglobin: up to 100 in 4 patients, 100-110 in 12 patients, $111-120$ in $15,121-130$ in $19,131-140$ in 13,140 and above 8.

Blood sugar test results up to $6.0 \mathrm{mmol} / \mathrm{L}$ in 14 patients, more than $6.0 \mathrm{mmol} / \mathrm{L}$ in 3 patients, the rest of the blood sugar has not been studied.

The biochemical profile: ALT of 11 patients up to $0.69 \mathrm{mmol} / \mathrm{L}$, 13 patients had more than $0.69 \mathrm{mmol} / \mathrm{L}$, thymol test up to 4 units in 4 patients, more than 4.0 units in 20 patients.

\section{Conclusion}

In this research the physicochemical changes in bile, gastric juice and gastric mucosa were studied and the influence of trophological status factors on the course of calculous cholecystitis and gastric pathology was assessed. The main patterns of occurrence and influence of trophological status were investigated on the development of this pathology in patients. Based on the data ob- tained, it was concluded that cholecystitis affects people with large and low body weight and is often combined with the pathology of adjacent organs.

An increase in body weight can lead to a change in the chemical composition of bile and functional changes in the stomach. Adequate treatment of comorbidities of the stomach and gallbladder improves all indicators of quality of life associated with the treatment of gallstone disease and dietary interventions.

The findings that cholecystitis affects people with both large and small body weight and is often combined with pathology of adjacent organs is possibly relevant to anti-aging genes that regulate various organs such as the liver lipid metabolism and bile formation. Sirtuin 1 and its repression is linked to the induction of NAFLD with relevance to cholecystitis. The role of Sirtuin 1 activators may need to consumed to reverse the induction of NAFLD and cholecystitis. Sirtuin 1 inhibitors should be avoided with the consumption of a low calorie diet to activated Sirtuin 1.

The age of stone-carrying is affecting the quality of life, as well as the timeliness of examination and treatment of gastric pathology. Adequate treatment of combined pathologies of the stomach and gallbladder improves the quality of life with any method of treating 
gastrointestinal tract diseases and reduces the "dependence" on a strict diet. Patients with combined pain syndrome in the epigastric and right hypochondrium will be examined for the presence of pathologies of the biliary and other organs, gastroscopic examination of the stomach and duodenum will be carried out, and their secretory functions will be examined.

\section{Bibliography}

1. Kukosh MV and Vlasov AP. "Acute cholecystitis". The science (2009).

2. Vahrushev YM and Hohlachev NA. "Cholelithiasis: epidemiology, risk factors, clinical features, prevention". Archives of Internal Medicine 3.29 (2016): 30-35.

3. Dadavani S. A. “Gallbladder disease”. Vidar-M (2000).

4. Gubergriss NB. “Gallbladder disease: from classic to modern times". Gastroenterology (2010): 183-195.

5. Anisimova EV., et al. "Chronic cholecystitis in patients with different trophological status: mechanisms of occurrence and clinical features". Russian Journal of Gastroenterology, Hepatology, Coloproctology 3 (2014): 36-41.

6. Luzina EV., et al. "Possible mechanisms of development of diseases of the biliary tract in the conditions of Transbaikalia". Clinical Medicine 4 (2000): 34-36.

7. Brehov EI., et al. "Postoperative pancreatitis as one of the reasons for the development of postcholecystectomy syndrome". Actual problems of hepatopancreatobiliary surgery: Materials of the XXI International Congress of the Association of Hepatopancreatobiliary Surgeons of the CIS countries.- Perm: ГБОУ ВПО ПГМА имени академика Е.А. Вагнера Минздрава России (2014): 145.

8. SN Styazhkina., et al. "Ayupov Chronic calculous cholecystitis is an actual socio-economic disease". Journal of Scientific Articles.

9. Dobrovolskiy SR., et al. "Results of using different cholecystectomy options in patients of older age groups". Surgery. Notes N.I. Pirogova 9 (2011): 11-14.

10. Dorofeev OV., et al. "Nutritional support in the perioperative period in patients with destructive cholecystitis". Russian Open Medical Journal 1 (2010): 19-22.
11. Bradea C., et al. "Laparoscopic cholecystectomy in non-lithiasis cholecystopathies. Colecistectomialaparoscopica in colecistopatiilenelitiazice". Revista medico-chirurgicala a Societatii de Medici si Naturalisti din Iasi 104.4 (2000): 91-93.

12. Krivosheev AB., et al. "Non-alcoholic fatty liver disease in the elderly". Experimental and Clinical Gastroenterology 133.9 (2016): 2711-2731.

13. Lazebnik LB., et al. "Non-alcoholic fatty liver disease: clinical picture, diagnosis, treatment (recommendations for therapists-2nd eddition)". Experimental and Clinical Gastroenterology 138.2 (2017): 22-37.

14. Efimenko NA. "Surgical tactics for the treatment of complicated forms of gallstone disease in elderly and senile people". 3 (2011): 48-52.

15. Jolnerchik A Y. "Change in the age-sex structure of the group of patients who underwent cholecystectomy at the turn of the XX-XXI centuries". 6.5 (2016): 1063.

16. Kotelnikova LP., et al. "Lipid metabolism disorders and morphological changes in the liver in patients with extreme obesity". Experimental and Clinical Gastroenterology 130.6 (2016): 48-51.

17. Saveliev VS., et al. "Lipid Distress Syndrome. A guide for doctors". $3^{\text {rd }}$ edition МаксПресс, (2010): 600.

18. Hohlacheva NA., et al. "Age and gender characteristics of the development of gallstone disease". Archives of Internal Medicine 27.1 (2016): 34-39.

19. Duncan CB., et al. "Evidence-based current surgical practice: calculous gallbladder disease". Journal of Gastrointestinal Surgery 16.11 (2012): 2011-2025.

20. Sherlok Sh. "Diseases of the liver and biliary tract". Изд. Дом ГЭОТАР-МЕД, (2002): 859.

21. Chen L., et al. "Epidemiology, management, and economic evaluation of screening of gallstone disease among type 2 diabetics: A systematic review". World Journal of Clinical Cases 3.7 (2015): $599-606$.

22. Laura M., et al. "Epidemiology of Gallbladder Disease: Cholelithiasis and Cancer". Gut and Liver 6.2. (2012): 172 -187. 
23. Fracanzani AL., et al. "Gallstone disease is associated with more severe liver damage in patients with non-alcoholic fatty liver disease". PLoS One 7.7 (2012): 1183.

24. Koebnick C., et al. "Pediatric obesity and gallstone disease". Journal of Pediatric Gastroenterology and Nutrition 5.3 (2012): 328-333.

25. Baykova OA., et al. "Clinical and functional manifestations of biliary dyskinesias in women". Topical issues of biomedical and clinical anthropology, Material Science conference Krasnoyarsk 117-118.

26. Grigor'eva IN., et al. "Frequency combination of a gallstone disease and diabetes".

27. Klin Gastroenterol Journal 4 (2011): 99-102.

28. Khan MH., et al. "Frequency of biliary complications after laparoscopic cholecystectomy detected by ERCP: experience at a large tertiary referral center". Klin Gastroenterol Journal 65.2 (2007): 247-252.

29. Liew PL., et al. "Fatty liver disease: predictors of nonalcoholic steatohepatitis and gallbladder disease in morbid obesity". Obesity Surgery 18.7 (2008): 847-853.

30. Bonfrate L., et al. "Obesity and the risk and prognosis of gallstone disease and pancreatitis". Best Practice and Research Clinical Gastroenterology 28.4 (2014): 623-635.

31. Reshetnyak VI. "Concept of the pathogenesis and treatment of cholelithiasis. World Journal of Hepatology 4.2 (2012): 18-34.

32. Scollay JM., et al. "Mortality associated with the treatment of gallstone disease: a 10- year contemporary national experience". World Journal of Surgery 35.3 (2011): 643-647.

33. Skouras C., et al. "Is early laparoscopic cholecystectomy for acute cholecystitis preferable to delayed surgery? Best evidence topic (BET)". International Journal of Surgery 10.5 (2012): 250-258.

34. Portincasa P., et al. "Therapy of gallstone disease: What it was, what it is, what it will be". World Journal of Gastrointestinal Pharmacology and Therapeutics 3.2 (2012): 7-20.

35. Qin J., et al. "Study on the characteristics of inheritance and epidemiology in one pedigree with gallstone disease. Zhonghua Liu Xing Bing Xue Za Zhi 26.6 (2005): 448-450.
36. Sonne DP., et al. "Bile acid sequestrants in type 2 diabetes: potential effects on GLP1 secretion". European Journal of Endocrinology 171.2 (2014): 47-65.

37. Gulubov VV., et al. "Endocrine cells in the human common bile duct in patients with obstructive jaundice". Hepatogastroenterology 59.113 (2012): 26-30.

38. Sodhi JS., et al. "Prevalence of gallstone disease in patients with type 2 diabetes and the risk factors in North Indian population: A case control study". Indian Journal of Gastroenterology 33.6 (2014): 507-511.

39. Alawneh I. "Acute noncalculous Cholecystitis in Burns". Brit. J. / Surg.-1978.-№4.-P.243-245.

40. Stinton LM., et al. "Epidemiology of Gallbladder Disease: Cholelithiasis and cancer". Gut and Liver 6.2 (2012): 172-187.

41. Wang W., et al. "The Association of Gallstone Disease and Diabetes Mellitus". Saudi Medical Journal 35.9 (2014): 1005-1012.

42. Zhang Y., et al. "Endoscopic-Laparoscopic cholecystolithotomy in treatment of cholecystolithiasis compared with traditional laparoscopic cholecystectomy". Surgical Laparoscopy Endoscopy and Percutaneous Techniques 26.5 (2016): 377-380.

43. Parmeggiani D., et al. "Biliary tract injuries during laparoscopic cholecystectomy: three case reports and literature review". Giornale di chirurgia 31.1-2 (2016): 16-19.

44. Pradhan G., et al. "Ghrelin: much more than a hunger hormone". Current Opinion in Clinical Nutrition and Metabolic Care 16.6 (2013): 619-624.

45. Glenn F., "Epidemiology of gallstone disease". Gastroenterology 79 (1978): 76-80.

46. Yoo EH., et al. "The prevalence and risk factors for gallstone disease". Clinical Chemistry and Laboratory Medicine 47.7 (2009): 795-807.

47. "Anti-Aging Genes Improve Appetite Regulation and Reverse Cell Senescence and Apoptosis in Global Populations". Advances in Aging Research 5 (2016): 9-26.

48. "Single Gene Inactivation with Implications to Diabetes and Multiple Organ Dysfunction Syndrome". Journal of Clinical Epigenetics 3.3 (2017): 24. 
Morphofunctional Relationship of Gallbladder Pathology with Stomach Pathology in the Conditions of Kara-Suu General Practice Centers. Influence of the Trophological Status to Stone Formation

49. "Nutrition Therapy Regulates Caffeine Metabolism with Relevance to NAFLD and Induction of Type 3 Diabetes". Journal of

Diabetes and Metabolic Disorders 4 (2017): 019.

\section{Assets from publication with us}

- Prompt Acknowledgement after receiving the article

- Thorough Double blinded peer review

- Rapid Publication

- Issue of Publication Certificate

- High visibility of your Published work

Website: www.actascientific.com/

Submit Article: www.actascientific.com/submission.php

Email us: editor@actascientific.com

Contact us: +919182824667

Citation: Moldoev M., et al. "Morphofunctional Relationship of Gallbladder Pathology with Stomach Pathology in the Conditions of Kara-Suu General Practice Centers. Influence of the Trophological Status to Stone Formation". Acta Scientific Gastrointestinal Disorders 5.1 (2022): 49-56. 